\title{
Bilateral Retinal Problem in a Patient With Alport Syndrome.
}

\author{
Sundeep K. Kasi \\ Thomas Jefferson University \\ Murtaza K Adam \\ Thomas Jefferson University \\ David S Ehmann \\ Thomas Jefferson University
}

Follow this and additional works at: https://jdc.jefferson.edu/willsfp

Part of the Ophthalmology Commons

Let us know how access to this document benefits you

\section{Recommended Citation}

Kasi, Sundeep K.; Adam, Murtaza K; and Ehmann, David S, "Bilateral Retinal Problem in a Patient With Alport Syndrome." (2017). Wills Eye Hospital Papers. Paper 73.

https://jdc.jefferson.edu/willsfp/73

This Article is brought to you for free and open access by the Jefferson Digital Commons. The Jefferson Digital Commons is a service of Thomas Jefferson University's Center for Teaching and Learning (CTL). The Commons is a showcase for Jefferson books and journals, peer-reviewed scholarly publications, unique historical collections from the University archives, and teaching tools. The Jefferson Digital Commons allows researchers and interested readers anywhere in the world to learn about and keep up to date with Jefferson scholarship. This article has been accepted for inclusion in Wills Eye Hospital Papers by an authorized administrator of the Jefferson Digital Commons. For more information, please contact: JeffersonDigitalCommons@jefferson.edu. 


\section{JAMA Ophthalmology Clinical Challenge \\ Bilateral Retinal Problem in a Patient With Alport Syndrome}

Sundeep K. Kasi, MD; Murtaza K. Adam, MD; David S. Ehmann, MD

A Fundus photograph

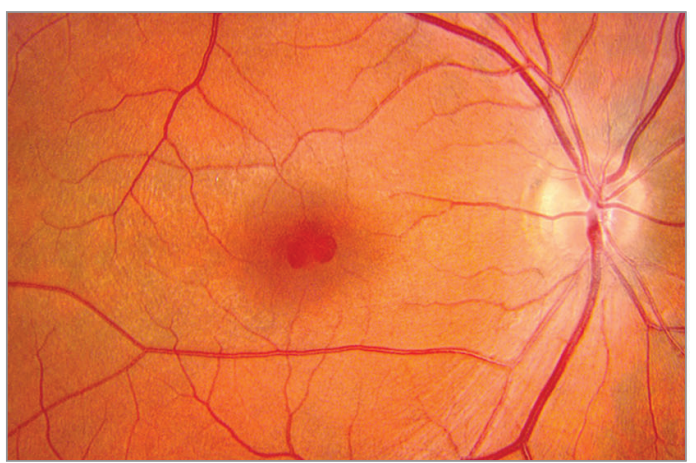

B Optical coherence tomography

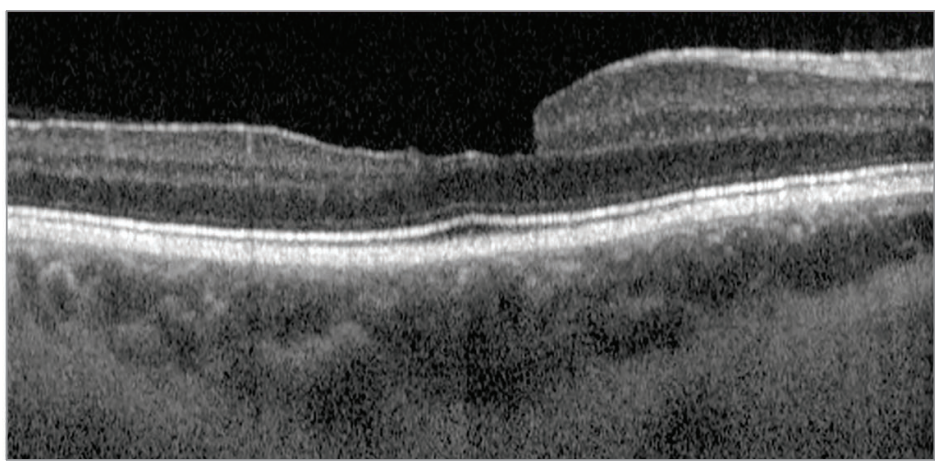

Figure. A, Color fundus photograph demonstrating pseudohole formation with pigment mottling, right eye. B, Spectral-domain optical coherence tomography revealing distortion of foveal contour without epiretinal membrane formation, right eye. Similar examination and optical coherence tomographic findings were present in the left eye.

A man in his late 20s with a history of Alport syndrome presented on referral for a bilateral retina problem after experiencing right-sided herpes zoster ophthalmicus. He denied risk factors for human immunodeficiency virus, and serologic testing results were negative. He had completed treatment for keratouveitis and reported some residual blurring of his vision in the right eye. His ocular history was unremarkable. His uncorrected visual acuity was $20 / 60$ OD and $20 / 40$ OS. Pupillary responses, confrontation visual fields, motility, external examination, and intraocular pressure were normal. Slitlamp examination revealed superficial keratitis and anterior stromal haze in the right eye but otherwise was normal. Fundus examination (Figure, A) revealed a poor foveal light reflex with an irregularshaped area of red discoloration in the fovea and surrounding subtle flecking of the retina in both eyes. No other abnormalities were found on ophthalmoscopic examination. Spectraldomain optical coherence tomography (Figure, B) showed an irregular foveal contour with trace epiretinal membrane formation, with no evidence of foveoschisis or outer retinal changes. Fundus autofluorescence was normal.

\section{WHAT WOULD YOU DO NEXT?}

A. Perform pars plana vitrectomy with internal limiting membrane peeling

B. Perform aqueous/vitreous tap for viral polymerase chain reaction and inject foscarnet intravitreally

C. Observe and repeat spectraldomain optical coherence tomography in 6 months to 1 year

D. Perform intravitreal injection of ocriplasmin 


\section{Diagnosis}

Lamellar macular hole, both eyes

\section{What to Do Next}

C. Observe and repeat spectral-domain optical coherence tomography in 6 months to 1 year

\section{Discussion}

Alport syndrome can be associated with multiple ocular findings including macular pathologies such as lamellar or full-thickness macular holes. ${ }^{1}$ In this case, a macular pseudohole is seen clinically, and optical coherence tomographic examination reveals a lamellar macular hole with intact outer retina. Vitrectomy with membrane peeling should be offered for symptoms of distortion owing to epiretinal membrane formation or substantial retinal changes such as cystoid abnormalities, disruption of the ellipsoid zone, and full-thickness macular hole formation. Ocriplasmin has been shown to be most successful in selected cases of vitreomacular adhesion and may induce closure of small full-thickness macular holes, neither of which are seen in this case. The clinical examination does not suggest worsening herpetic retinitis after completion of treatment for keratouveitis, so intravitreal antivirals are not indicated. Therefore, observation with serial examination and optical coherence tomography are warranted for this case.

Alport syndrome is a genetic disorder of type IV collagen, with consequent systemic abnormalities in basement membrane production manifesting as glomerulonephritis, hearing loss, and ocular changes. Most commonly, Alport syndrome is inherited in an X-linked fashion (85\%), followed by autosomal recessive fashion (10\%-15\%), and rarely by autosomal dominant fashion. ${ }^{1}$ Described ocular abnormalities include posterior polymorphous corneal dystrophy, corneal clouding owing to accumulation of mucopoly- saccharides, conjunctival telangiectasia, anterior lenticonus, cataract, and retinal flecks as well as macular holes. ${ }^{1}$ These findings are often absent in childhood and become more apparent with aging. ${ }^{2}$ While dot and fleck retinopathy is the most common ocular sign of Alport syndrome (85\%), ${ }^{3}$ a range of macular pathology from lamellar macular holes to giant macular holes have been reported as well as vitelliform lesions and foveal and midperipheral retinoschisis. ${ }^{4-6}$

It is suspected that these macular pathologies may be secondary to abnormalities in type IV collagen, causing weakness of the internal limiting membrane. Others postulate that abnormal type IV collagen in the Bruch membrane may allow collection of intraretinal fluid within the retina prior to hole formation ${ }^{7}$ or that an anomalous vitreoretinal interface may also contribute to vitreomacular interface abnormalities. ${ }^{1}$

Although the development of these macular abnormalities is not well understood, a few observational case reports have shown that lamellar macular holes can transform into full-thickness macular holes. ${ }^{4,6}$ Interestingly, Shah et al $^{4}$ documented the coalescence of multiple small macular holes into a single large macular hole. Progressive vision loss is a distinct possibility in patients with Alport syndrome with early macular changes such that monitoring with fundus examination as well as optical coherence tomography might be appropriate in some cases where disruption of the outer retina or full-thickness macular hole formation may improve with internal limiting membrane peeling.

\section{Patient Outcome}

The patient was informed of the association of Alport syndrome and lamellar macular hole and asked to return with any new symptoms of metamorphopsia or reduced vision. He was followed up, and repeated refraction was performed after the corneal haze improved with best-corrected visual acuity of 20/30 OU.

\section{ARTICLE INFORMATION}

Author Affiliations: The Retina Service of Wills Eye Hospital and Mid Atlantic Retina, Thomas Jefferson University, Philadelphia, Pennsylvania.

Corresponding Author: Sundeep K. Kasi, MD, The Retina Service of Wills Eye Hospital, Thomas Jefferson University, 840 Walnut St, Ste 1020, Philadelphia, PA 19107 (sundeepkasi@gmail.com).

Published Online: June 8, 2017. doi:10.1001/jamaophthalmol.2017.0036

Author Contributions: Dr Sundeep had full access to all of the data in the study and takes responsibility for the integrity of the data and the accuracy of the data analysis.
Conflict of Interest Disclosures: The author has completed and submitted the ICMJE Form for Disclosure of Potential Conflicts of Interest and none were reported.

\section{REFERENCES}

1. Scassa C, Cupo G, Bruno M, lervolino R, Scarinci F, Giusti C. Early lamellar macular hole in Alport syndrome: case report and review of the literature. Eur Rev Med Pharmacol Sci. 2012;16(1):122-125.

2. Hentati N, Sellami D, Makni K, et al. Ocular findings in Alport syndrome: 32 case studies [in French]. J Fr Ophtalmol. 2008;31(6, pt 1):597-604.

3. Blasi MA, Rinaldi R, Renieri A, et al. Dot-and-fleck retinopathy in Alport syndrome caused by a novel mutation in the COL4A5 gene. Am J Ophthalmol. 2000;130(1):130-131.
4. Shah SN, Weinberg DV. Giant macular hole in Alport syndrome. Ophthalmic Genet. 2010;31(2): 94-97.

5. Fawzi AA, Lee NG, Eliott D, Song J, Stewart JM. Retinal findings in patients with Alport Syndrome: expanding the clinical spectrum. $\mathrm{Br} J$ Ophthalmol. 2009;93(12):1606-1611.

6. Thomas AS, Baynham JT, Flaxel CJ. Macular holes, vitelliform lesions, and midperipheral retinoschisis in Alport syndrome. Retin Cases Brief Rep. 2016;10(2):109-111.

7. Mete UO, Karaaslan C, Ozbilgin MK, Polat S, Tap O, Kaya M. Alport's syndrome with bilateral macular hole. Acta Ophthalmol Scand. 1996;74(1):77-80. 